\title{
Determination of the physical and mechanical properties of moso, guadua and oldhamii bamboo assisted by robotic fabrication
}

\author{
Rodolfo Lorenzo ${ }^{1 *}$, Martha Godina ${ }^{1}$, Leonel Mimendi ${ }^{1}$ and Haitao Li $^{2}$
}

\begin{abstract}
The large-scale urbanisation taking place in the developing world requires the construction industry to adopt alternative non-conventional renewable materials to reduce the unsustainable level of greenhouse gas emissions associated with the production of industrialised building materials. Bamboo is one of the most promising non-conventional building materials endemic to most developing countries, but there is still insufficient consistent information on the physical and mechanical properties of the numerous species suitable for construction. This study shows the potential of robotic fabrication to accelerate testing programmes on small clear samples of bamboo required to compare physical and mechanical properties across different species and differing plantation management practices. This fabrication method is applied on an experimental testing programme to determine the characteristic values of density, compressive strength, elastic modulus and shear strength of Phyllostachys pubescens (moso), Guadua angustifolia Kunth (guadua) and Guadua angustifolia (oldhamii). The efficient development of comprehensive experimental datasets of clear samples of bamboo is fundamental to inform the development of future design guidelines for bamboo as a construction material.
\end{abstract}

Keywords: Bamboo, Physical and mechanical properties, Small clear samples, Robotic fabrication

\section{Introduction}

The construction industry currently generates $40 \%$ of greenhouse gas emissions in cities and the world's urban population is expected to grow from 3.5 to 5 billion by 2030 with $95 \%$ of the urban expansion taking place in the developing world [1]. The three main construction materials-steel, concrete and aluminium-are already responsible for almost $50 \%$ of all global industrial $\mathrm{CO}_{2}$ emissions with demand expected to double by 2050 [2].

Construction at this massive scale will undoubtedly require the construction industry to adopt alternative non-conventional sustainable materials. For decades,

\footnotetext{
*Correspondence: r.lorenzo@ucl.ac.uk

${ }^{1}$ Department of Civil, Environmental and Geomatic Engineering, University College London, Gower Street, London WC1E 6BT, UK Full list of author information is available at the end of the article
}

bamboo in its natural form (culms or poles) has been identified as one of the most promising non-conventional building materials endemic to most developing countries [3] due to its very fast growth rate and remarkable strength-to-weight ratio $[4,5]$. However, there is still insufficient basic information on its physical and mechanical properties to understand and manage its inherent variability among the approximately 100 species so far identified suitable for construction [6] and the effects of differing growing conditions, treatment methods and other mostly unregulated plantation management practices. Previous studies [7-11] have focused on the determination of the physical and mechanical properties of different species based on sample sizes ranging from full culms to micro-samples. To some extent, the variability in sample sizes 
and testing methods together with the limited number of test results to date have prevented the development of a consistent and comprehensive knowledge base on the physical and mechanical properties of bamboo. The influence of sample size and testing method on the wide range of properties found in the literature is illustrated in Table 1 for Phyllostachys pubescens (moso) and Guadua angustifolia Kunth (guadua), two of the most popular bamboo species in the world.

The evaluation of the physical and mechanical properties of small clear specimens of bamboo is fundamental to increase our understanding of its performance as a structural material and support the classification and comparison of different species. Similar to wood [19], standardised testing of small clear specimens of bamboo is necessary due to the large number of species available and the inherent variability of the material. Also, specimen size, imperfections and other factors are likely to have a more significant effect on the more complex tests on full culm sections [20].

This study describes the use of modern robotic fabrication as an efficient technique to support the intensive fabrication of small clear samples of bamboo poles in industrial settings. Clear samples of three different bamboo species are used to determine their characteristic values of density, compressive strength, elastic modulus and shear strength including a correlation analysis with density and fibre content as potential grading parameters for bamboo. These results provide a consistent comparison basis through the adoption of a single testing standard [21].

The bamboo procured for this study is representative of the commercially available material in three global regions with very different levels of industrial development reflected in distinct local plantation management practices and treatment methods. Treatment methods in particular are likely to modify the internal structure of bamboo to varying degrees which in turn can affect its mechanical properties, as shown by Daud et al. [22] for leaching and by Yongqian et al. [23] for carbonisation treatments. Additional comparison studies beyond the scope of this work are required to study the effect of these complex factors on the properties of bamboo which further justifies the need to adopt efficient and consistent fabrication and testing methods for clear bamboo samples.

\section{Materials and methodology}

Three different bamboo species from Latin America and China were chosen for this study as detailed in Table 2 . Mature poles were harvested and treated on site following the local supplier's practices. In general, the purpose of treatments is to protect bamboos against fungi, decay and splitting [24, 25]. The treatment used for guadua and Bambusa oldhamii (oldhamii) was leaching \& air-drying in which poles are submerged in a solution of borax and boric acid for approximately 1 week and subsequently air-dried for 3-4 weeks on well-ventilated racks protected from direct sunlight [26]. On the other hand, a

Table 1 Summary of physical and mechanical properties of moso and guadua bamboo

\begin{tabular}{|c|c|c|c|c|c|}
\hline References & $\begin{array}{l}\text { Compression strength } \\
\text { (MPa) }\end{array}$ & $\begin{array}{l}\text { Compression modulus } \\
\text { (GPa) }\end{array}$ & Shear strength (MPa) & Density $\left(\mathrm{kg} / \mathrm{m}^{3}\right)$ & $\begin{array}{l}\text { Moisture } \\
\text { content \% }\end{array}$ \\
\hline \multicolumn{6}{|l|}{ Moso } \\
\hline [12] & $46-63^{\mathrm{a}}$ & - & - & - & - \\
\hline [7] & $49.5^{\mathrm{a}}$ & - & - & - & $5-20^{b}$ \\
\hline [8] & $48-114^{a}$ & $3.6-11^{\mathrm{a}}$ & - & $464-1287^{b}$ & $5-20^{b}$ \\
\hline$[9]$ & $69.1^{c}$ & $10.56^{c}$ & - & $630^{c}$ & 7 \\
\hline [13] & - & - & - & $1180^{b}$ & - \\
\hline [11] & - & - & - & $710^{\mathrm{b}}$ & $12.5^{\mathrm{b}}$ \\
\hline [14] & - & - & $15-20^{b}$ & - & $15^{b}$ \\
\hline \multicolumn{6}{|l|}{ Guadua } \\
\hline [15] & $28^{\mathrm{a}}$ & $15^{\mathrm{a}}$ & $4^{c}$ & - & - \\
\hline [16] & $36.6-36.8^{a}$ & $16.3-17.9^{\mathrm{a}}$ & $7.1-7.8^{\mathrm{a}}$ & $663-764^{a}$ & $>30^{c}$ \\
\hline [17] & $20^{c, d}$ & - & $3-5^{c, d}$ & - & - \\
\hline [18] & $22-96^{a}$ & - & $4.5-14^{b}$ & - & - \\
\hline
\end{tabular}

\footnotetext{
a Based on full-size sample

b Based on clear samples

c Other samples

d Characteristic value
} 
Table 2 Bamboo properties

\begin{tabular}{|c|c|c|c|c|}
\hline Species & Origin & Age (years) & Treatment & $\begin{array}{l}\text { Avg. } \\
\text { diameter } \\
(\mathrm{mm})\end{array}$ \\
\hline Phyllostachys pubescens (moso) & Jiangsu, P.R.China & 3 to 4 & Carbonisation/env. chamber & 85 \\
\hline Guadua angustifolia Kunth (guadua) & Valle del Cauca, Colombia & 2 to 5 & Leaching/air-dried & 110 \\
\hline Bambusa oldhamii (oldhamii) & Veracruz, Mexico & 3 to 5 & Leaching/air-dried & 65 \\
\hline
\end{tabular}

carbonisation treatment was used for moso in which bamboo poles are placed in a horizontal carbonisation furnace at $75{ }^{\circ} \mathrm{C}, 45 \%$ of humidity and under a pressure of $1.60 \mathrm{MPa}$ for $90 \mathrm{~min}$. followed by 1-2 weeks on wellventilated racks protected from direct sunlight.

The Chinese industry standard JG/T 199-2007 [21] was adopted for this study as the most comprehensive source currently available for the experimental testing of the mechanical and physical properties of small clear specimens. Following this standard, samples were extracted from the internodes at each end of bamboo poles of approximately $2.8 \mathrm{~m}$ in length. This study focused on three mechanical tests: (a) compressive elastic modulus parallel to the fibre; (b) compressive strength parallel to the fibre and (c) shear strength parallel to the fibre. Specimens for each of these tests were extracted from two diametrically opposite areas within each end internode as shown in Fig. 1 together with the details of the test specimens. The number of test samples for each of the three mechanical tests considered in this study was 80, 81 and 137 for moso, guadua and oldhamii, respectively. All samples were kept at a constant temperature of $20{ }^{\circ} \mathrm{C} \pm 2{ }^{\circ} \mathrm{C}$ and relative humidity of $65 \% \pm 5 \%$ for 14 days according to the requirements in JG/T 199-2007 [21].

Due to the unavailability of robotic fabrication equipment on site in China and Mexico, moso and oldhamii samples were fabricated using traditional manual tools. In contrast, all 81 guadua samples were robotically fabricated at University College London using a 1-kW Kress 1050 FME-1 milling motor mounted on a compact six-axis Kuka Agilus KR 10 R1100 [27] industrial robot. In addition, a low-cost 3D laser scanner [28] with

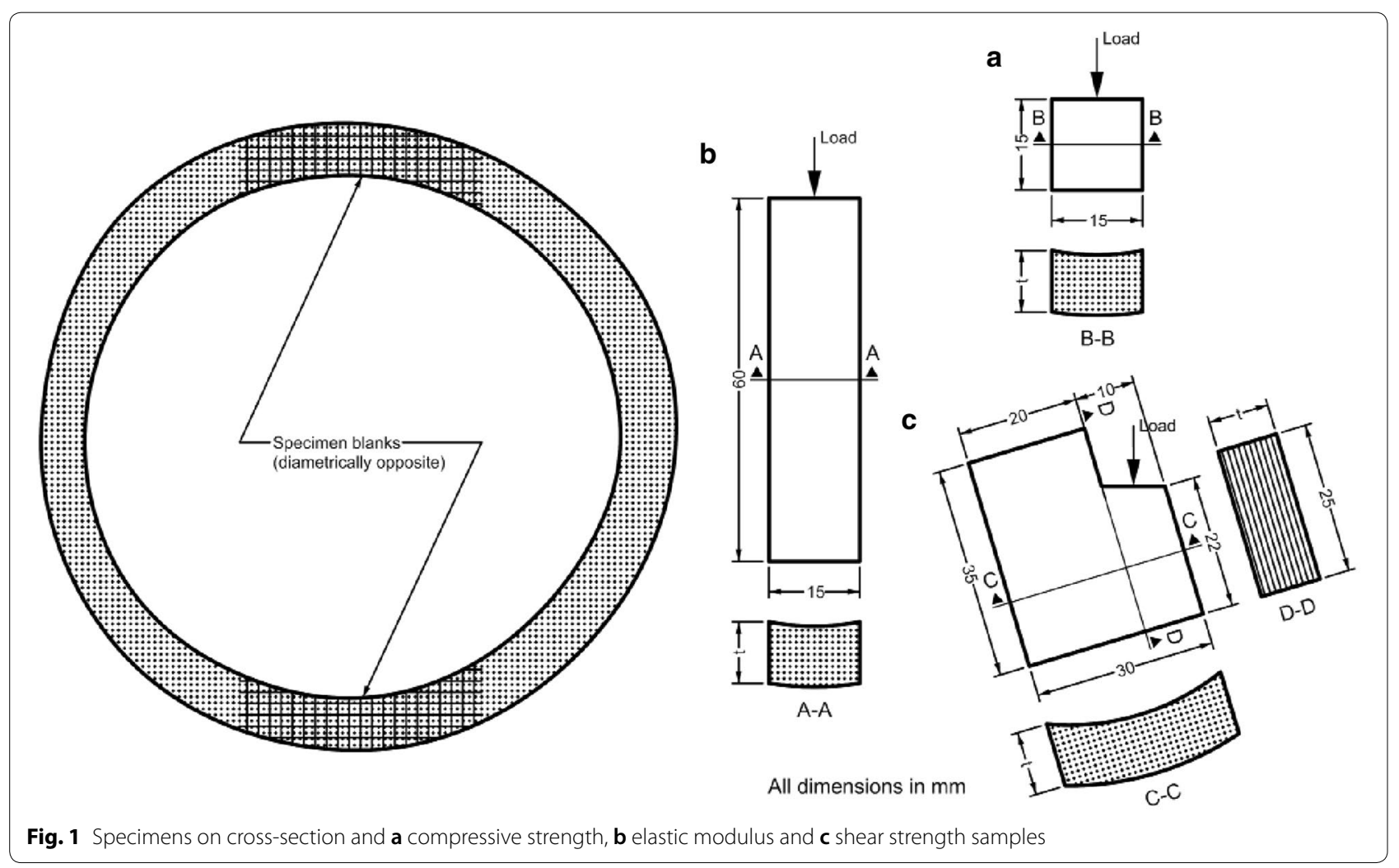


a precision of up to $0.5 \mathrm{~mm}$ was mounted on the robot flange alongside the milling motor (Fig. 2) for the implementation of a semi-automated fabrication workflow for intensive bamboo sampling. This sensor is used to generate an accurate digital polygon mesh model [29] of the portion of bamboo pole to be fabricated. In order to eliminate the inherent scanning noise, this raw mesh is subsequently transformed into a Non-uniform Rational Basis Spline (NURBS) [30] surface using the extensive function library in Rhino3D [31]. This NURBS surface is generated based on a series of NURBS curves (Order: 3; Control points: 20) obtained from cross sections of the mesh at $2 \mathrm{~mm}$ spacings. The centroidal axis of the tube defined by these sections and the resulting NURBS surface provide the basis to generate the relevant robot toolpaths using the software KUKA|prc [32] according to the organic and individual geometry of each pole (Fig. 3). Due to the fibrous nature of bamboo, the adopted milling cutter is a YG-1, 6 mm diameter, high-speed steel (HSS), multiflute, coarse-pitch ripper. The recommended speed and feed for the milling operation are $8000 \mathrm{rpm}$ and $8 \mathrm{~mm} / \mathrm{s}$, respectively. Figure 4 shows some typical robotically fabricated mechanical test samples together with the end of

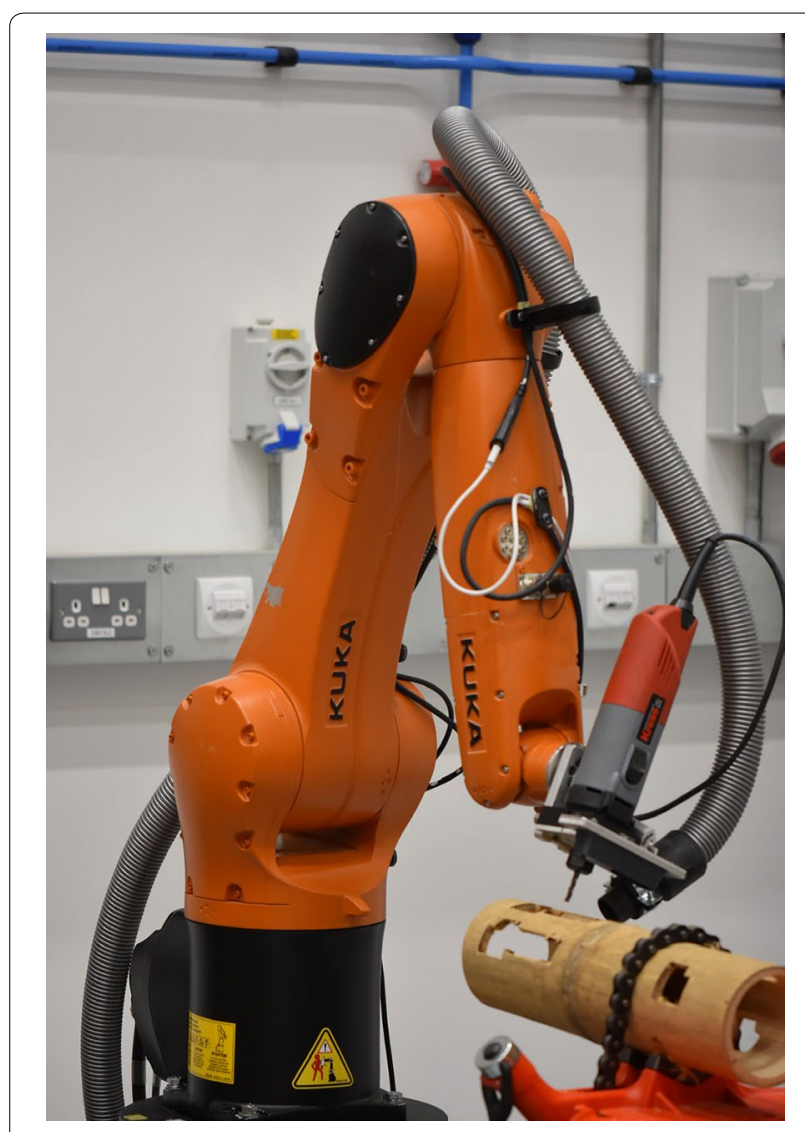

Fig. 2 Industrial robot with milling motor and 3D scanner

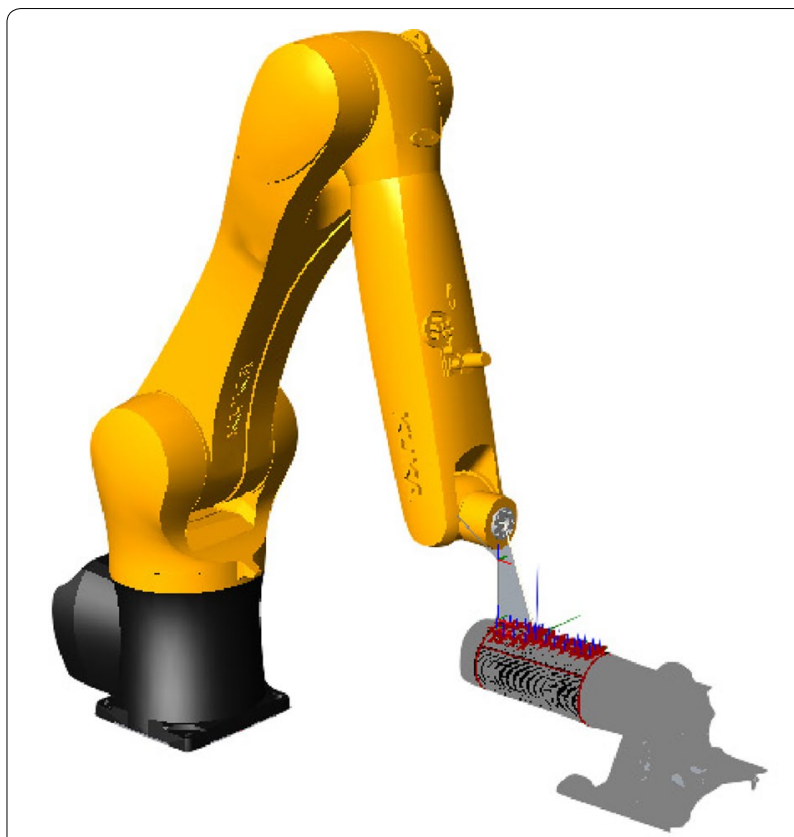

Fig. 3 Robot toolpath generation with KUKA|prc (Robots in architecture 2018)

a machined bamboo pole illustrating the position of the samples' holding tabs and the clean finish produced by the milling operation.

The mechanical testing machine used in this study was an electro-mechanical, single-column Instron 3345 with a maximum capacity of $5 \mathrm{kN}$. Compressive strength samples requiring a higher load were tested on a $300-\mathrm{kN}$ Controls UNIFLEX universal frame. The testing accessories consisted of compression platens with integral spherical seats, an Instron 2630 clip-on strain gauge extensometer for the compressive elastic modulus tests and the relevant testing jig for the shear strength tests as described in JG/T

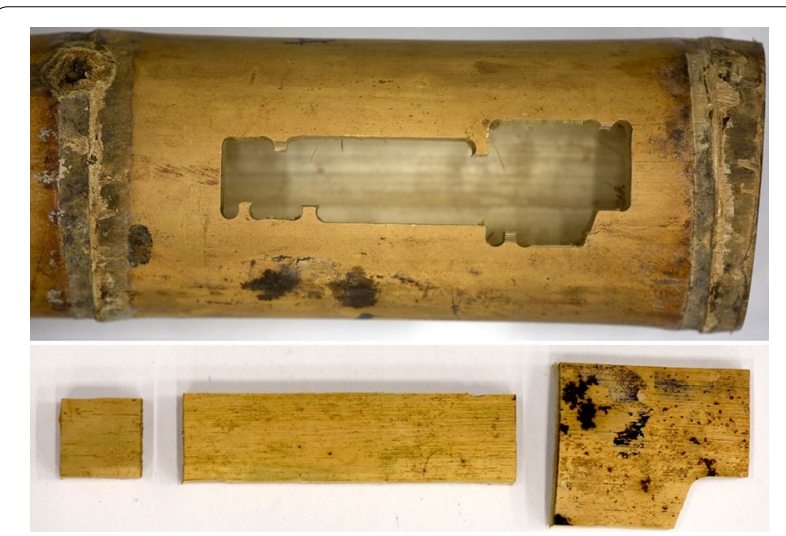

Fig. 4 Robotically fabricated small clear samples 
199-2007 [21]. The robotic fabrication toolpath for the shear sample and the holding piece restraining the top of the sample in the corresponding test jig were designed to accommodate the internal radiused corner produced by the milling operation so as to maintain the position of the sample's critical shear plane (Section D-D, Fig. 1c) as shown in Fig. 5.

\section{Results}

Experimental testing and calculations were conducted according to the standard JG/T 199-2007 [21] including those for the determination of the samples' moisture content. All test results were adjusted to a reference moisture content of $12 \%$ applying the appropriate correction coefficients in this standard. In a parallel exercise, the moisture content results were used to calibrate the portable Delmhorst BD-2100 moisture meter [33] as a more practical tool to efficiently determine the moisture content in bamboo specimens.

Characteristic values for density, modulus of elasticity, compressive strength and shear strength were determined for each species according to Annex D: Design Assisted by Testing in BS EN 1990:2002 [34]:

$$
X_{k(n)}=m_{X}\left\{1-k_{n} V_{X}\right\},
$$

where $X_{k(n)}$ is the characteristic value; $n$ the number of test results; $m_{X}$ the mean of the $n$ sample results; $k_{n}$ the characteristic fractile factor for the $5 \%$ characteristic value (Table D1 of CEN [34]) and $V_{X}$ the coefficient of variation.

The coefficient of variation, $V_{X}$, was taken from JG/T 199-2007 [21], if available, and also calculated from BS EN 1990:2002 [34] for comparison:

$$
V_{X}=\frac{s_{X}}{m_{X}}
$$

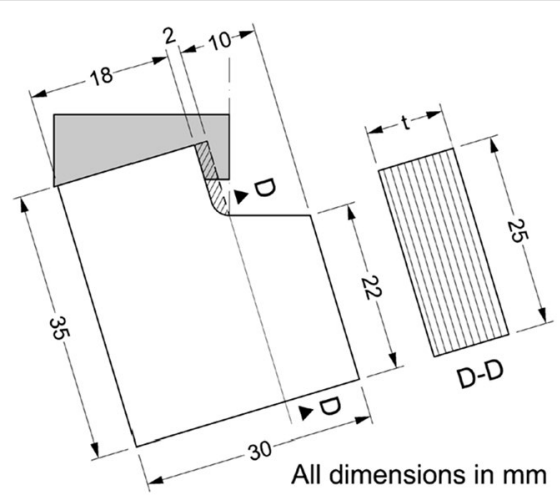

Fig. 5 Detail of robotically fabricated shear sample and matching jig holding piece where $s_{X}$ is the value of the standard deviation given by:

$$
s_{X}^{2}=\frac{1}{n-1} \sum\left(x_{i}-m_{X}\right)^{2}
$$

and $x$ is the observed value for each sample.

All numerical parameters and results presented in this section are summarised in Table 3.

\section{Dry density}

The dry density, $\rho_{0}$, of all samples was calculated as [21]:

$$
\rho_{0}=\frac{m_{0}}{V_{0}}
$$

where $m_{0}$ and $V_{0}$ are the mass and volume of the fully dried sample.

Table 3 presents the mean, standard deviation and characteristics values for the density of all three species.

\section{Compressive strength parallel to the fibre}

The compressive strength parallel to the fibre, $f_{\mathrm{c}}$, at $12 \%$ moisture content was calculated as [21]:

$$
f_{\mathrm{c}}=K_{f_{\mathrm{c}}} \frac{P_{\max }}{b t},
$$

where $P_{\max }$ is the ultimate load; $b$ and $t$ the specimen width and thickness and $K_{f_{c}}$ is the correction factor for the effect of moisture content given by:

$$
K_{f_{\mathrm{c}}}=\frac{1}{0.79+1.5 e^{-0.16 w}}
$$

and $w$ is the moisture content of the sample at the time of testing.

Table 3 shows the mean, standard deviation and characteristic values for the compressive strength of all three species.

\section{Elastic modulus parallel to the fibre}

The elastic modulus parallel to the fibre, $E_{\mathrm{C}}$, at $12 \%$ moisture content was calculated as [21]:

$$
E_{\mathrm{c}}=K_{E_{\mathrm{c}}} \frac{\Delta \sigma}{\Delta \varepsilon},
$$

where $\Delta \sigma$ is the stress difference between the minimum (5 MPa) and maximum (20 MPa) stress limits; $\Delta \varepsilon$ is the deformation difference measured at the stress limits and $K_{E_{\mathrm{c}}}$ is the correction factor for the effect of the moisture content given by:

$$
K_{E_{\mathrm{c}}}=\frac{1}{0.89+0.36 e^{-0.1 w}}
$$

and $w$ is the moisture content of the sample at the time of testing. 
Table 3 Summary of results

\begin{tabular}{|c|c|c|c|c|c|c|c|}
\hline \multirow[t]{2}{*}{ Property } & \multirow[t]{2}{*}{ Mean } & \multirow[t]{2}{*}{ Std. dev. } & \multicolumn{2}{|c|}{ JG/T 199-2007 } & \multicolumn{2}{|c|}{ BS EN 1990} & \multirow[t]{2}{*}{ Charac. value } \\
\hline & & & $v_{x}(\%)$ & $k_{n}$ & $v_{x}(\%)$ & $k_{n}$ & \\
\hline \multicolumn{8}{|l|}{ Moso } \\
\hline Density $\left(\mathrm{kg} / \mathrm{m}^{3}\right)$ & 684 & 97 & 10 & 1.66 & 14 & 1.67 & 522 \\
\hline Compressive strength (MPa) & 54 & 8 & 13 & 1.66 & 16 & 1.67 & 40 \\
\hline Elastic modulus (MPa) & 11,930 & 2628 & - & - & 22 & 1.67 & 7529 \\
\hline Shear strength (MPa) & 16 & 2 & 20 & 1.66 & 11 & 1.67 & 11 \\
\hline Volume fraction & 0.33 & 0.04 & - & - & - & - & - \\
\hline \multicolumn{8}{|l|}{ Guadua } \\
\hline Density $\left(\mathrm{kg} / \mathrm{m}^{3}\right)$ & 730 & 52 & 10 & 1.66 & 10 & 1.67 & 608 \\
\hline Compressive strength (MPa) & 58 & 12 & 13 & 1.66 & 21 & 1.67 & 38 \\
\hline Elastic modulus (MPa) & 18,480 & 3570 & - & - & 19 & 1.67 & 12,502 \\
\hline Shear strength (MPa) & 12 & 2 & 20 & 1.66 & 18 & 1.67 & 8 \\
\hline Volume fraction & 0.42 & 0.04 & - & - & - & - & - \\
\hline \multicolumn{8}{|l|}{ Oldhamii } \\
\hline Density $\left(\mathrm{kg} / \mathrm{m}^{3}\right)$ & 734 & 83 & 10 & 1.65 & 11 & 1.66 & 595 \\
\hline Compressive strength (MPa) & 68 & 11 & 13 & 1.65 & 16 & 1.66 & 50 \\
\hline Elastic modulus (MPa) & 20,683 & 7868 & - & - & 38 & 1.66 & 7604 \\
\hline Shear strength (MPa) & 13 & 3 & 20 & 1.65 & 22 & 1.66 & 8 \\
\hline Volume fraction & 0.46 & 0.06 & - & - & - & - & - \\
\hline
\end{tabular}

$V_{x}$ coefficient of variation; $k_{n}$, characteristic fractile factor

a Based on the governing values of $V_{X}$ and $k_{n}$ (i.e. largest $V_{X} k_{n}$ product)

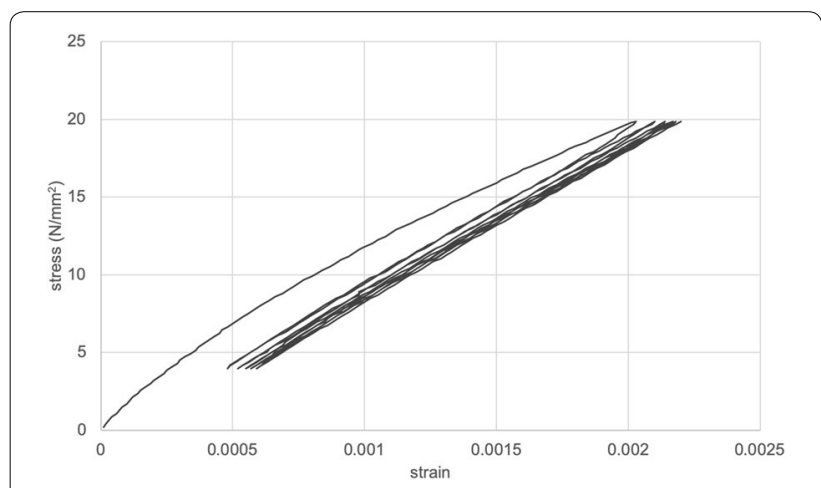

Fig. 6 Typical experimental stress-strain curve for elastic modulus test

The typical experimental stress-strain curve in Fig. 6 shows how the behaviour of the sample stabilises after the six loading and unloading cycles specified in JG/T 199-2007 [21]. According to this standard, the average deformation difference from the last three loading cycles was used to calculate the elastic modulus, $E_{\mathrm{c}}$, of each sample.

Table 3 shows the mean, standard deviation and characteristic values for the elastic modulus of all three species.

\section{Shear strength parallel to the fibre}

The shear strength parallel to the fibre, $f_{\mathrm{v}}$, at $12 \%$ moisture content was calculated as [21]:

$$
f_{\mathrm{v}}=K_{f_{\mathrm{v}}} \frac{P_{\max }}{l t}
$$

where $P_{\max }$ is the ultimate load; $l$ and $t$ the length and thickness of critical shear section (Section D-D in Fig. 1) and $K_{f_{\mathrm{v}}}$ is the correction factor for the effect of moisture content given by:

$$
K_{f_{\mathrm{v}}}=\frac{1}{0.67+0.77 e^{-0.07 w}}
$$

and $w$ is the moisture content of the sample at the time of testing.

Table 3 shows the mean, standard deviation and characteristics values for the shear strength of all the three species.

\section{Volume fraction}

Bamboo can be considered as a natural fibre-reinforced composite formed of high-strength unidirectional (axial) fibres and conducting vessels embedded in a matrix of parenchyma ground tissue [4] as shown in the X-ray phase-contrast microscopy [35] image in Fig. 7. As such, the volume fraction, or ratio between the fibre content and the total sample volume, was calculated based on the 


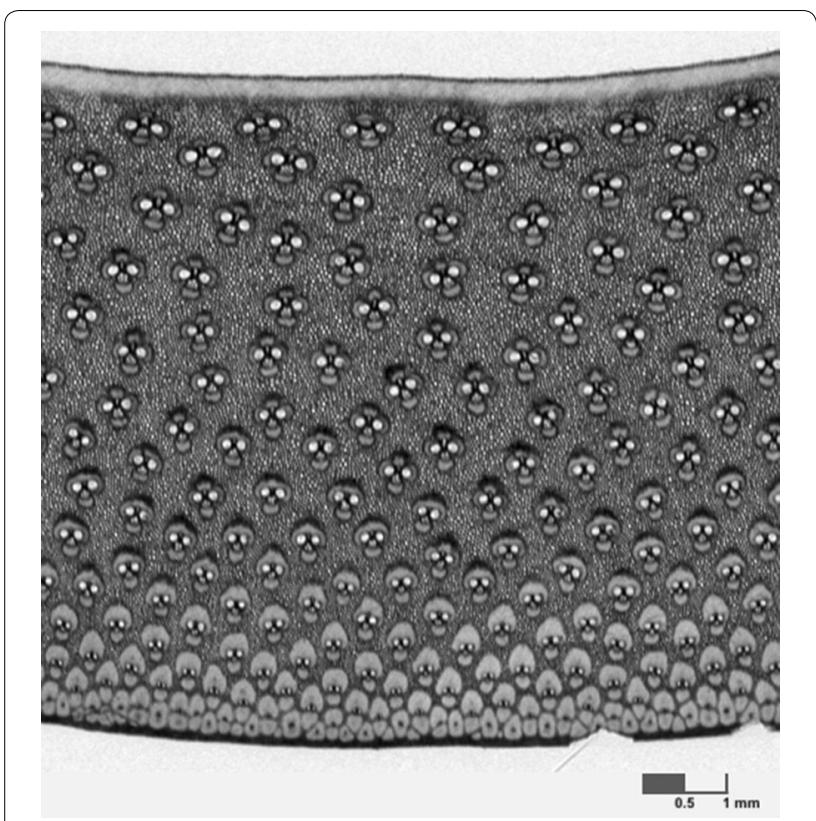

Fig. 7 X-ray phase-contrast microscopy image of a section of bamboo wall (moso)

digital processing of images taken from cross sections of each of the two specimen blanks in Fig. 1. These cross sections were lightly sanded with $600 / 1200$ grit silicon carbide sanding paper prior to capturing their image with a Nikon D7200 camera equipped with an AF-S DX Micro NIKKOR $85 \mathrm{~mm} \mathrm{f/3.5G} \mathrm{ED} \mathrm{VR} \mathrm{lens.} \mathrm{Typical} \mathrm{images} \mathrm{are}$ presented in Fig. 8 showing the variability in fibre content and their distribution pattern among different species. The volume fraction calculated from the captured images neglects the contribution from the small hollow conducting vessels clustered around fibre bundles shown in Fig. 7 as they constitute only less than approximately $8 \%$ of the total cross-sectional area [4]. Figure 8 also shows the corresponding post-processed binary images from which the area of fibres was calculated using a bespoke Matlab script [36]. This script converts the original RGB image into a greyscale intensity image (Matlab function: rgb2gray) and filters any significant noise from it (Matlab function: imgaussfilt, 0.1 standard deviation). The script then calculates, based on the greyscale image histogram, the threshold value of pixel intensity (Matlab function: graythresh) that differentiates fibre bundles and matrix. This value is subsequently used to generate the final binary image (Matlab function: imbinarize) from which pixel areas for fibre bundles and matrix are quantified.

The mean and standard deviation of the volume fraction for all three species are presented in Table 3.

\section{Correlation and normality test}

Figures 9 and 10 show individual density and volume fraction values plotted against the measured mechanical properties for each species. The Pearson correlation coefficients [37] for all individual samples are shown in Table 4, together with the corresponding correlation coefficients considering only the mean values of these properties for each species (Table 3). Figure 11 shows mean density and volume fraction values plotted against the mean mechanical properties for each species.

The characteristic values (Table 3 ) and correlation coefficients (Table 4) calculated assume that all experimental data follow a normal distribution. This normal distribution hypothesis was tested according to ISO 5479:1997 [38] for a significance level of 0.05 and the results of

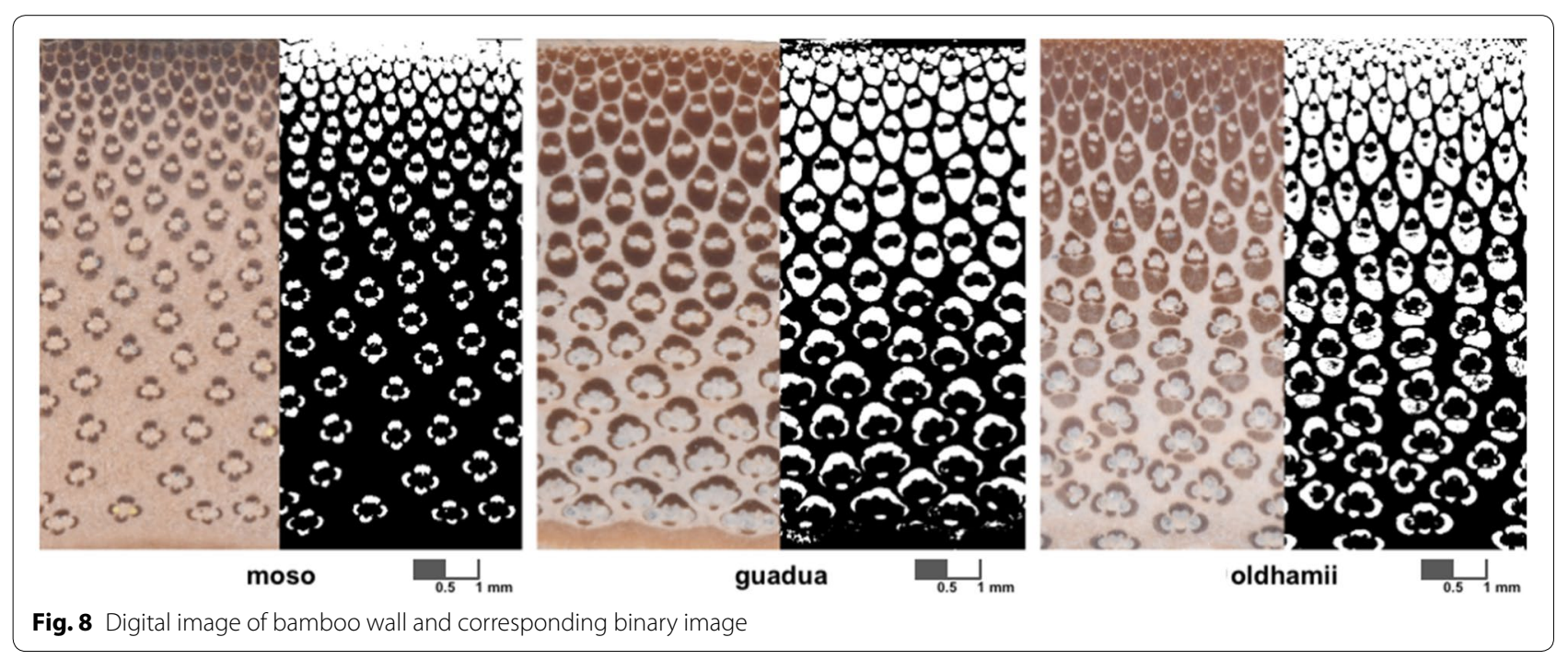



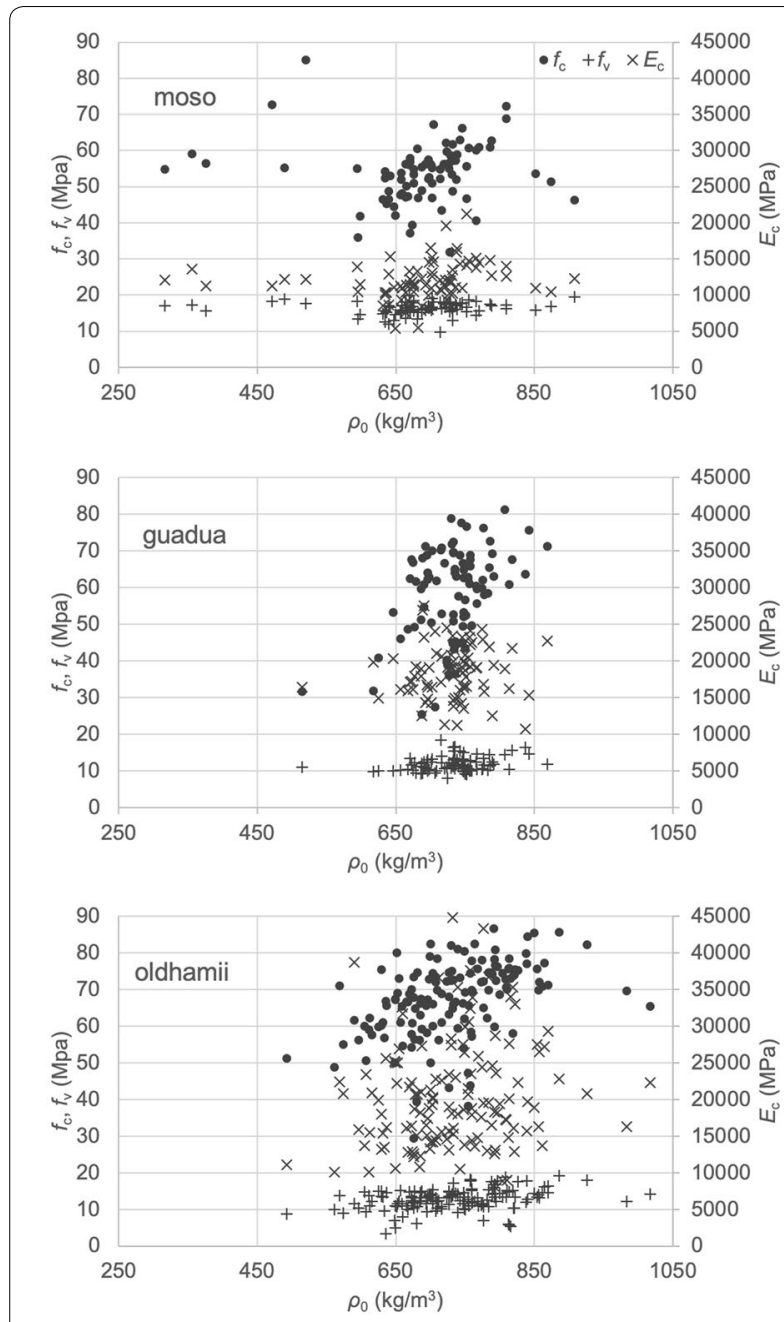

Fig. 9 Correlation between density and mechanical properties

directional tests for both skewness and kurtosis are summarised in Table 5.

\section{Discussion}

The advancement of bamboo as a sustainable construction material still requires considerable experimental testing on small clear samples to gather the basic information needed to understand and manage the inherent variability of its physical and mechanical properties and the effects of differing plantation management practices. The irregular geometry of bamboo poles together with the size and intricacy of the required small clear samples make the use of manual fabrication processes a relatively challenging and inefficient solution for the production of the large number of samples required to build significant datasets. As shown in this study, the use of modern, and increasingly affordable, 3D scanning and robotic fabrication technologies, can support
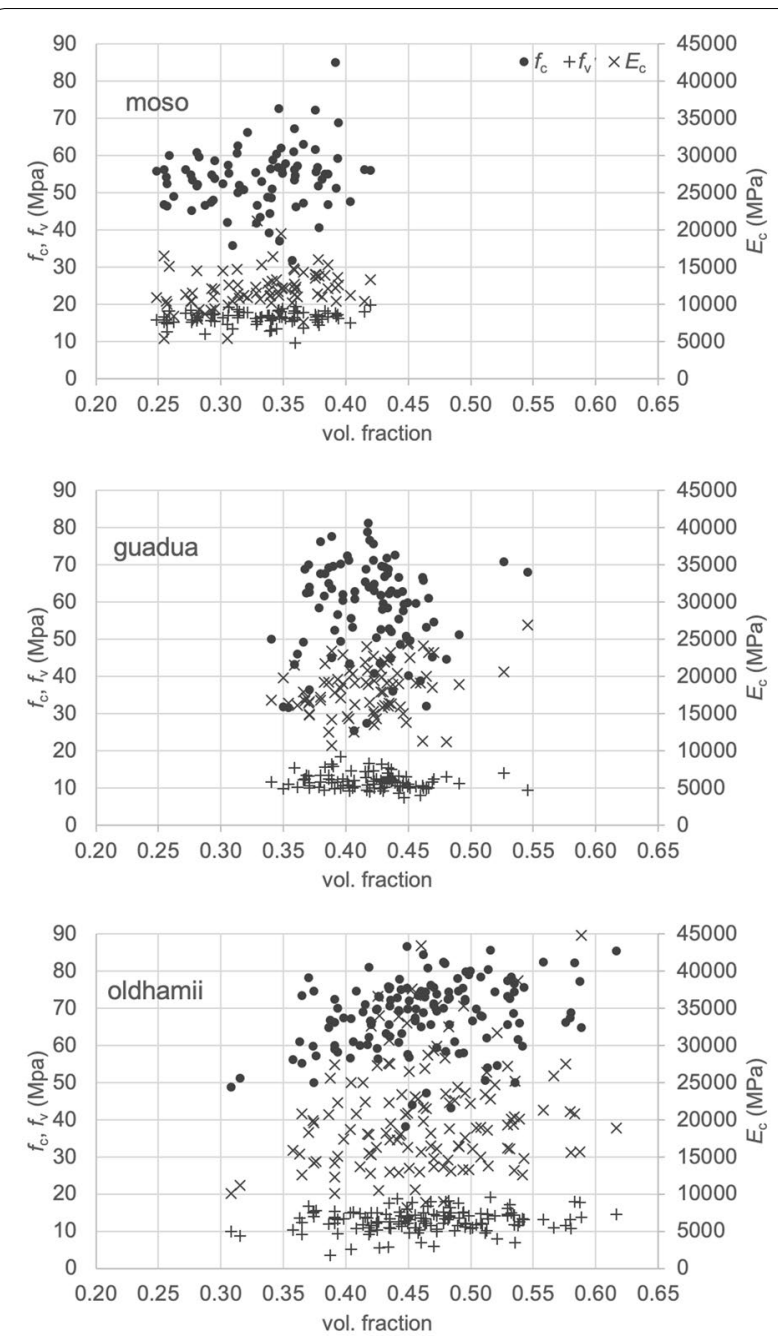

Fig. 10 Correlation between volume faction and mechanical properties

the intensive and efficient sampling of bamboo poles in industrial settings to accelerate the data collection process and advance our knowledge on the properties of different bamboo species.

The physical and mechanical properties of all three species studied (Table 3) are within the range of values for moso and guadua found in previous studies (Table 1) noting that equivalent information for oldhamii was not found in the literature. The results for each species show a significant degree of variability which, as expected, is responsible for the relatively large difference between the mean and characteristic values of all the tested properties. Moreover, all samples in this study were cut only from the bottom part of the felled culms and so this variability is expected to increase if samples are taken from other parts of the culms due to the change in fibre content found along the length of bamboo culms [39]. 
Table 4 Pearson correlation coefficients

\begin{tabular}{lcc}
\hline Property & Density & Volume fraction \\
\hline Compressive strength & & \\
Moso & -0.019 & 0.175 \\
Guadua & 0.170 & 0.305 \\
Oldhamii & 0.063 & 0.168 \\
All species $^{\text {a }}$ & 0.787 & 0.927 \\
Elastic modulus $^{\text {Moso }}$ & & \\
Guadua & 0.427 & 0.005 \\
Oldhamii $_{\text {All species }}{ }^{\mathrm{a}}$ & 0.065 & 0.281 \\
Shear strength $^{\text {Moso }}$ & 0.276 & -0.076 \\
Guadua $_{\text {Oldhamii }}$ & 0.984 & 0.995 \\
All species $^{\mathrm{a}}$ & & \\
\hline
\end{tabular}

${ }^{a}$ Based on the mean values for each species (Table 3)

The Pearson correlation coefficients for all individual samples do not show any significant correlation between density or volume fraction and any of the mechanical properties studied (Table 4). This indicates that neither density nor volume fraction would be suitable parameters to adopt as the basis for a potential grading system for bamboo poles. On the contrary, the corresponding correlation coefficients considering only the mean values of these properties for each species show a relatively strong correlation (Fig. 11). This correlation agrees with the established notion that compressive strength and stiffness increase for denser species with higher fibre content as both matrix and fibres are likely to be mobilised to act as a composite element to resist axial effects. It also suggests that shear strength reduces for denser species with higher fibre content as the matrix constitutes the main resisting component (due to the orientation of the fibres) and its density is $2-3$ times lower than that of the fibres [9].
Table 5 Normal distribution directional test results

\begin{tabular}{|c|c|c|c|c|}
\hline \multirow[t]{2}{*}{ Property } & \multicolumn{2}{|c|}{ Skewness } & \multicolumn{2}{|c|}{ Kurtosis } \\
\hline & Value & Limit $^{\mathrm{a}}$ & Value & Limit $^{\mathrm{a}}$ \\
\hline \multicolumn{5}{|l|}{ Moso } \\
\hline Density & 1.48 & 0.43 & 7.18 & 2.08 \\
\hline Compressive strength & 0.41 & & 4.87 & \\
\hline Elastic modulus & 0.54 & & 4.79 & \\
\hline Shear strength & 0.95 & & 4.77 & \\
\hline \multicolumn{5}{|l|}{ Guadua } \\
\hline Density & 0.62 & 0.43 & 5.99 & 2.08 \\
\hline Compressive strength & 0.63 & & 2.89 & \\
\hline Elastic modulus & 0.15 & & 2.74 & \\
\hline Shear strength & 0.80 & & 3.58 & \\
\hline \multicolumn{5}{|l|}{ Oldhamii } \\
\hline Density & 0.24 & 0.34 & 3.68 & 2.27 \\
\hline Compressive strength & 0.55 & & 4.09 & \\
\hline Elastic modulus & 1.17 & & 4.69 & \\
\hline Shear strength & 0.49 & & 3.79 & \\
\hline
\end{tabular}

${ }^{a}$ Based on a 0.05 significance level

Directional tests to assess the normality of the experimental results show that, apart from the skewness of the compressive strength in moso, elastic modulus in guadua and density in oldhamii, all other data deviate from a normal distribution to varying degrees (Table 5). No previous knowledge exists on the probability distributions of the physical and mechanical properties of bamboo and so it is not possible to draw any definite conclusions on the significance of this deviation based only on the relatively limited results of this study. These results have been nonetheless calculated based on the assumption of a normal distribution in order to provide an initial benchmark for further studies to assess the suitability of this and other probability distribution models subject to the future availability of comprehensive and consistent experimental datasets for these and other species.

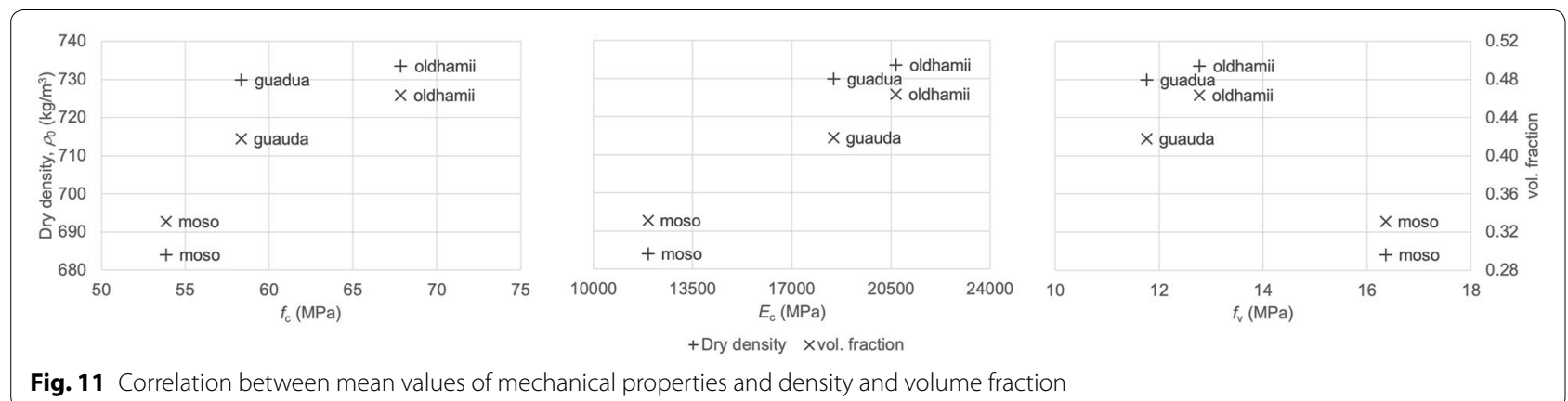

Fig. 11 Correlation between mean values of mechanical properties and density and volume fraction 


\section{Conclusions}

This paper presents the results of a comprehensive experimental testing programme to determine the characteristic values of density, compressive strength, elastic modulus and shear strength of small clear samples of moso, guadua and oldhamii bamboo. The robotic fabrication of some of these samples demonstrates the potential of modern technologies to accelerate testing programmes on small clear samples that can contribute to build significant experimental datasets on different bamboo species. The results of this work show the importance of experimental testing on small clear samples as a simple and reliable method to determine and compare the physical and mechanical properties of bamboo species potentially suitable for construction. More generally, the development of a consistent and comprehensive knowledge base on test results of small clear samples can help to understand and manage the relatively large variability of these properties to inform the development of future design guidelines for bamboo as a construction material.

\begin{abstract}
Abbreviations
$b$ : Width of the specimen; $E_{c}$ : Elastic modulus parallel to the fibre; $f_{c}$ : Compressive strength parallel to the fibre; $f_{\mathrm{v}}$ : Shear strength parallel to the fibre; HSS: High-speed steel; $K_{E_{C}}$ : Elastic modulus correction factor for moisture content effect; $K_{f_{c}}$ : Compressive strength correction factor for moisture content effect; $K_{f}:$ Shear strength correction factor for moisture content effect; $k_{n}$ : Characteristic fractile factor; I: Length of critical section; $m_{0}$ : Dried mass; $m_{x}$ : Mean of $n$ samples; $n$ : Number of test results; NURBS: Non-uniform rational basis spline; $P_{\text {max }}$ : Ultimate load; $S_{x}$ : Standard deviation; $t$ : Thickness of the specimen; $V_{0}$ : Dried volume; $V_{x}$ : Coefficient of variation; $w$ : Moisture content of sample at the time of testing; $x$ : Observed value for each sample; $X_{k}$ : Characteristic value; $\Delta_{\varepsilon}$ : Deformation difference measured at the stress limits; $\Delta_{\sigma}$ : Stress difference between the stress limits; $\rho_{0}$ : Oven dry density.
\end{abstract}

\section{Acknowledgements}

The authors would like to thank Dr. Gerardo Oliva-Salinas and Mr. David Trujillo for enabling the procurement of the bamboo samples used in this study as well as Dr. Chuhee Lee for her support during the experimental programme.

\section{Authors' contributions}

$\mathrm{RL}$ and $\mathrm{HL}$ oversaw and reviewed the overall research. $\mathrm{RL}$ analysed the experimental data and wrote the manuscript while MG and LM executed all the practical activities of the work. All authors read and approved the final manuscript.

\section{Funding}

The work presented in this paper was supported by the UK Engineering and Physical Sciences Research Council (EPSRC) (Grant Nos: EP/M017702/1 and EP/ P510890/1) and the British Council/CSC UK-China Joint Research and Innovation Partnership Fund (Ref UK-276080305).

\section{Availability of data and materials}

The datasets used and/or analysed during the current study are available from the corresponding author on reasonable request.

\section{Competing interests}

The authors declare that they have no competing interests.

\section{Author details}

${ }^{1}$ Department of Civil, Environmental and Geomatic Engineering, University College London, Gower Street, London WC1E 6BT, UK. ${ }^{2}$ College of Civil
Engineering, Nanjing Forestry University, 159 Longpan Road, Nanjing 210037, People's Republic of China.

Received: 16 December 2019 Accepted: 9 March 2020

Published online: 12 March 2020

\section{References}

1. UN-HABITAT (2013) 53 UN-Habitat Model Projects. United Nations Human Settlements Programme, Nairobi

2. Allwood J, Cullen J (2011) Sustainable materials — with both eyes open: future buildings, vehicles, products and equipment. UIT Cambridge Ltd, Cambridge

3. Vorontsova MS, Clark LG, Dransfield J, Govaerts R, Wilkinson T, Baker WJ (2016) World checklist of bamboos and rattans. International Network for Bamboo and Rattan, Beijing

4. Liese W (1998) The anatomy of bamboo culms. International Network for Bamboo and Rattan, Beijing

5. Janssen JJA (2000) Designing and building with bamboo. International Network for Bamboo and Rattan, Beijing

6. Kaminski S, Lawrence A, Trujillo D (2016) Structural use of bamboo Part 1: introduction to bamboo. Struct Eng 94(8):40-43

7. Albermani F, Goh GY, Chan SL (2007) Lightweight bamboo double layer grid system. Eng Struct 29:1499-1506. https://doi.org/10.1016/j.engst ruct.2006.09.003

8. Chung KF, Yu WK (2002) Mechanical properties of structural bamboo for bamboo scaffoldings. Eng Struct 24(4):429-442. https://doi.org/10.1016/ s0141-0296(01)00110-9

9. Dixon PG, Gibson LJ (2014) The structure and mechanics of moso bamboo material. J R Soc Interface 11:20140321. https://doi.org/10.1098/ rsif.2014.0321

10. Taylor D, Kinane B, Sweeney C, Sweetnam D, O'Reilly P, Duan K (2015) The biomechanics of bamboo: investigating the role of the nodes. Wood Sci Technol 49:345-357. https://doi.org/10.1007/s00226-014-0694-4

11. Shao ZP, Fang CH, Huang SX, Tian GL (2010) Tensile properties of moso bamboo (phyllostachys pubescens) and its components with respect to its fiber-reinforced composite structure. Wood Sci Technol 44:655-666. https://doi.org/10.1007/s00226-009-0290-1

12. Lo TY, Cui HZ, Tang PWC, Leung HC (2008) Strength analysis of bamboo by microscopic investigation of bamboo fibre. Constr Build Mater 22:1532-1535. https://doi.org/10.1016/j.conbuildmat.2007.03.031

13. Nogata F, Takashi $H$ (1995) Intelligent functionally graded material: bamboo. Compos Eng 5:743-751. https://doi.org/10.1016/09619526(95)00037-N

14. Motoi $O$ (1955) Studies on the properties of bamboo stem (part 13). Kyushu University Institutional Repository. https://doi.org/10.15017 114967

15. Trujillo D (2007) Bamboo structures in Colombia. Struct Eng 85(6):25-30

16. Correal DJF, Arbeláez CA (2010) Influence of age and height position on Colombian Guadua Angustifolia bamboo mechanical properties. Maderas Ciencia y Tecnología 12(2):105-113. https://doi.org/10.4067/s0718-221×2 010000200005

17. Kaminski S, Lawrence A, Trujillo D, Feltham I, López LF (2016) Structural use of bamboo Part 3: design values. Struct Eng 94(12):42-45

18. Hidalgo LO (1978) Nuevas técnicas de construcción con bambú. Estudios Técnicos Colombianos Ltda. Universidad Nacional de Colombia, Bogotá, pp 26-137

19. ASTM (2014) Standard Test Methods for Small Clear Specimens of Timber. D143-14, American Society of Material Testing International, West Conshohocken, US

20. ISO (2004) Bamboo_-Determination of physical and mechanical properties-part 1: requirements. ISO 22157-1:2004. International Organization for Standardization, Geneva

21. CNS (2007) Testing methods for physical and mechanical properties of bamboo used in building. JG/T 199-2007. China National Standards, Beijing

22. Daud NM, Nor NM, Yusof MA, Al Bakhri AAM, Shaari AA (2018) The physical and mechanical properties of treated and untreated Gigantochloa Scortechinii bamboo. AIP Conf Proc 1930:020016. https://doi. org/10.1063/1.5022910 
23. Yongqian $Y$, Hui X, Chengde L, Xiaozhen H (2011) Influences of carbonization on physical and mechanical properties of moso bamboo strips. J Bamboo Res 30(2):23-27

24. Kaminski S, Lawrence A, Trujillo D, King C (2016) Structural use of bamboo Part 2: durability and preservation. Struct Eng 94(10):38-43

25. Wu KT (1992) The effect of high-temperature drying on the antisplitting properties of Makino bamboo culm (Phyllostachys makinoi Hay). Wood Sci Technol 24:271-277. https://doi.org/10.1007/BF00200162

26. Morán J (2015) Construir con Bambú. International Network for Bamboo and Rattan, Beijing

27. Kuka Robotics (2018). https://www.kuka.com/en-gb/products/roboticssystems/industrial-robots/kr-agilus. Accessed 01 Oct 2018

28. Occipital (2018). https://occipital.com. Accessed 01 Oct 2018

29. Wikipedia (2018) Polygon mesh. https://en.wikipedia.org/wiki/Polyg on_mesh. Accessed 01 Oct 2018

30. Farin GE (1999) NURBS: From projective geometry to practical use. Peters Ltd, Natick

31. RMNA (2015) Rhinoceros 3D. Software Version 5.0, Robert McNeel \& Associates, Seattle, US

32. Robots in architecture (2018). Association for robots in architecture. https ://www.robotsinarchitecture.org/kuka-prc. Accessed 01 Oct 2018

33. Delmhorst (2018) Moisture meter BD-2100. https://www.delmhorst.com/ moisture-meters/bd-2100. Accessed 01 Oct 2018
34. CEN (2002) Eurocode-basis of structural design. BS EN 1990:2002 +A1:2005, European Commission for Standardization, Brussels

35. Endrizzi M, Vittoria FA, Diemoz PC, Lorenzo R, Speller RD, Wagner UH, Rau C, Robinson IK, Olivo A (2014) Phase-contrast microscopy at high X-ray energy with a laboratory setup. Opt Lett 39(11):3332-3335. https://doi. org/10.1364/OL.39.003332

36. MathWorks (2017) Matlab and image processing toolbox release $2017 \mathrm{~b}$. The MathWorks Inc., Natick

37. Cuningham CJL, Weathington BL, Pittenger DJ (2013) Understanding and conducting research in the health sciences. Chapter 10: Correlational Research. Wiley, New York. https://doi.org/10.1002/9781118643624.ch10

38. ISO (1997) Statistical interpretation of data_Part 7: Test for departure from normality. ISO 5479:1997. International Organization for Standardization, Geneva

39. Amada S, Ichikawa Y, Munekata T, Nagase Y, Shimizu H (1997) Fiber texture and mechanical graded structure of bamboo. Compos B 28B:13-20. https://doi.org/10.1016/b978-044482548-3/50119-0

\section{Publisher's Note}

Springer Nature remains neutral with regard to jurisdictional claims in published maps and institutional affiliations.

\section{Submit your manuscript to a SpringerOpen ${ }^{\circ}$ journal and benefit from:}

- Convenient online submission

- Rigorous peer review

- Open access: articles freely available online

- High visibility within the field

- Retaining the copyright to your article

Submit your next manuscript at $\boldsymbol{\nabla}$ springeropen.com 